\title{
Prevalence of Wuchereria bancrofti Infection in Mosquitoes from Pangani District, Northeastern Tanzania
}

\author{
Godlisten S. Materu ${ }^{a}$ \\ 'National Institute for Medical Research, Tukuyu Research Centre, Mbeya, Tanzania \\ Correspondence to Godlisten S. Materu (materu.godlisten@yahoo.com)
}

\begin{abstract}
Background: Wuchereria bancrofti is the most widely distributed of the 3 nematodes known to cause lymphatic filariasis, the other 2 being Brugia malayi and Brugia timori. Anopheles gambiae and Anopheles funestus are the main vectors. However, the relative contributions of mosquito vectors to disease burden and infectivity are becoming increasingly important in coastal East Africa, and this is particularly true in the urban and semiurban areas of Pangani District, Tanzania.

Methods: Mosquitoes were sampled from 5 randomly selected villages of Pangani District, namely, Bweni, Madanga, Meka, Msaraza, and Pangani West. Sampling of mosquitoes was done using standard Centers for Disease Control light traps with incandescent light bulbs. The presence of $W$. bancrofti in mosquitoes was determined via polymerase chain reaction (PCR) assays using NV1 and NV2 primers, and PoolScreen 2 software was used to determine the estimated rate of W. bancroffi infection in mosquitoes.

Results: A total of 951 mosquitoes were collected, of which $99.36 \%$ were Culex quinquefasciatus, $0.32 \%$ were Anopheles gambiae, and $0.32 \%$ other Culex species. The estimated rate of W. bancrofti infection among these mosquitoes was $3.3 \%$. Conclusion: This was the first study employing the use of PoolScreen PCR to detect W. bancroffi circulating in mosquito vectors in Pangani District, northeastern Tanzania. The presence of W. bancrofti infection suggests the possibility of infected humans in the area. The high abundance of $C x$. quinquefasciatus calls for integrated mosquito control interventions to minimise the risk of W. bancrofti transmission to humans. Further research is required to gain an in-depth understanding of the W. bancrofti larval stages in mosquitoes, their drug sensitivity and susceptibility profiles, and their fecundity.
\end{abstract}

\section{INTRODUCTION}

$W$ uchereria bancrofti is a filarial nematode that has a thread-like appearance in its adult stage. ${ }^{1}$ The female nematodes are about $10 \mathrm{~cm}$ long and $0.2 \mathrm{~mm}$ wide, while the males are only about $4 \mathrm{~cm}$ long. ${ }^{2}$ The adults reside and mate in the lymphatic system, where they can produce up to 50,000 microfilaria per day. ${ }^{1}$ The microfilariae are 250 to $300 \mu \mathrm{m}$ long, $8 \mu \mathrm{m}$ wide, and they circulate in the peripheral blood. They can live in the host as microfilaria for up to 12 months. Adult worms take 6 to 12 months to develop from the larval stage and can live between 4 and 6 years. ${ }^{3}$ The parasites are transmitted to humans when infected mosquito vectors deposit infective larvae onto the human skin. ${ }^{4}$ The larvae penetrate the skin, migrate to the lymphatic vessels, and develop into male and female adult worms over a period of months. Microfilaria ingested by a vector during a blood meal will develop to infective larvae in about 10 to 14 days. These migrate to the mosquito's proboscis and may then be transmitted to a new human host during a subsequent blood meal. Mosquitoes thus play an essen- tial role in maintaining the lifecycle of $W$. bancrofti and disseminating the infection. ${ }^{5}$

A blood smear is a simple and accurate diagnostic tool, provided the blood sample is taken during the day when the juveniles are in the peripheral circulation. ${ }^{6} \mathrm{~A}$ polymerase chain reaction (PCR) test can be performed to detect a minute fraction - as little as $1 \mathrm{pg}$ of filarial DNA. ${ }^{7}$ Some infected people do not have microfilaria in their blood. As a result, tests aimed to detect antigens from adult worms are used. Ultrasonography can also be used to detect the movements and noises caused by the movement of adult worms. ${ }^{8}$

Wuchereria bancrofti causes lymphatic filariasis, which is a disfiguring and disabling disease that is associated with severe suffering and socioeconomic burden in endemic communities. ${ }^{4}$ Current estimates suggest that more than 1 billion people living in endemic areas, who are at risk of the infection, and that more than onethird of these at-risk individuals are in sub-Saharan Africa. ${ }^{9}$ In Tanzania, about 34 million people are at risk, while 6 million people are already affected by lymphatic 
filariasis. Lymphatic filariasis is widespread in Tanzania; particularly high endemicity is seen along the coast of the Indian Ocean and in areas adjacent to the Great Lakes. ${ }^{10}$ In the Tanga Region of Tanzania, recent reports after mass drug administration (MDA) estimate circulating filiarial antigen (CFA) and microfilaraemia rates of $15.5 \%$ and $3.5 \%$, respectively, which are down by $75.5 \%$ and $89.6 \%$ - and $2.3 \%$ for CFA in school children - from baseline. ${ }^{13}$ Ongoing vector control measures against $W$. bancrofti in Tanzania consist of indoor residual spraying, long-lasting insecticidal nets, larval source management, mosquito repellents and coils, and house modifications.

It has previously been shown in Tanzania that MDA treatment regimen drastically reduce $W$. bancrofti microfilarial load. ${ }^{11}$ Other studies have revealed a decrease in the transmission of lymphatic filriasis associated with a decline in anopheline mosquitoes. ${ }^{17}$ Although a decline in anopheline mosquitoes has been documented in Tanga, information on vector burden and vector infection rate with $W$. bancrofti is still lacking. Therefore, this study assessed vector burden and vector infection rate with $W$. bancrofti.

\section{METHODS}

\section{Study Setting}

This study was carried out in 5 rural villages of Pangani District, which has an area of 1,830 $\mathrm{km}^{2}$, making it the smallest district in Tanga Region. It is located in the southern part of Tanga, extending from $5^{\circ} 15.5^{\prime}$ to $6^{\circ} \mathrm{S}$ and from $38^{\circ} 35^{\prime}$ to $39^{\circ} \mathrm{E}$. It is bordered by Handeni District to the west, the Indian Ocean to the east, Pwani Region to the south, and Muheza District to the North. Altitude ranges from 0 to $186 \mathrm{~m}$ above sea level. The Pangani District is administratively divided into 13 wards and 23 villages.

\section{Study Design}

This was an 8-month cross-sectional study, which involved the trapping of mosquitoes for laboratory examination of $W$. bancrofti. The 8 months were divided into 2 rounds, and 5 villages were randomly selected. Houses for mosquito collection were randomly selected from each village .The mosquitoes were sampled using using standard Centers for Disease Control light traps with incandescent light bulbs (Model 512, John W. Hock Company, Gainesville, FL, USA).

Traps were hung beside beds occupied by at least 1 person sleeping in unimpregnated bed nets. ${ }^{14}$ Briefly, the shield of each trap was left to touch the side of the net with $150 \mathrm{~cm}$ clearance above the floor. The light traps were set between 20:00 hours and 06:00 hours and retrieved in the morning at 06:00 hours.

\section{Mosquito Storage and Identification}

The mosquitoes collected at each village were held separately and transported to the National Institute for Medical Re- search's Tanga Centre for identification based on morphological identification keys. ${ }^{15,16}$ Female mosquitoes were organised into pools of 20, stored in cryogenic vials with silica gel, and transported to Sokoine University of Agriculture in Morogoro for screening of $W$. bancrofti.

\section{DNA Extraction from Mosquitoes}

DNA from the pools of 20 mosquitoes was extracted using a modified version of the Qiagen DNeasy kit protocol (Qiagen, Hilden, Germany). Briefly, mosquitoes were crushed in phosphate buffered saline, lysed, and then proteins were precipitated out using ethanol. The supernatant was passed through a silica column, followed by washing of the bound DNA. Afterwards, the silica was dried and DNA eluted into RNase-free Eppendorf tubes. DNA was stored at $-20{ }^{\circ} \mathrm{C}$ until PCR were done.

\section{Detection of W. bancrofti Using PCR}

PCR assays to detect $W$. bancrofti were performed using NV1 and NV2 primers. ${ }^{17,18}$ The target sequence for these primers is the Ssp I repeat, a gene present at $\sim 500$ copies per haploid genome. Amplification with these primers yields an $188 \mathrm{bp}$ fragment. Each $20 \mu \mathrm{l}$ PCR reaction contained $1 \times$ Qiagen Taq buffer; $50 \mathrm{Mm} \mathrm{MgCl}_{2} ; 50 \mathrm{mM}$ each of dATP, dCTP, dGTP, and dTTP; $10 \mathrm{pmol} / \mu \mathrm{l}$ of NV1 and NV2 primer; $1.25 \mathrm{U}$ HotStar Taq DNA polymerase; and $2 \mu \mathrm{l}$ genomic DNA. PCR reactions were run on a Veriti 96-Well Thermal Cycler (Applied Biosystems, Jurong, Singapore), and reaction conditions consisted of a single step of $95^{\circ} \mathrm{C}$ for 10 minutes, followed by $94^{\circ} \mathrm{C}$ for 30 s econds, $54^{\circ} \mathrm{C}$ for 45 seconds, and $72^{\circ} \mathrm{C}$ for 45 seconds. The final step was a 10 -minute extension at $72^{\circ} \mathrm{C}$. PCR products were size fractionated on $1.5 \%$ agarose gel stained with GelRed (Biotium, Hayward, CA, USA). Agarose gels were run at $100 \mathrm{~V}$ for 40 minutes and visualised under ultraviolet light using a gel documentation system (EZ Gel Imager, Bio-Rad Laboratories, Hercules, CA, USA). A positive control mosquito pool, known to be infected with $W$. bancrofti -a kind donation from the National Institute for Medical Research, Amani Tanga Centre - was used, along with negative controls, which were run concurrently with the samples to ensure that the PCR amplification was not contaminated. This helped prevent false positive results and ensure that all the reagents were working properly.

\section{Determination of Estimated Rate of W. Bancrofti Infection in Mosquito Vectors}

The calculation of vector infection rates from pool screening was addressed via an application of the binomial distribution. ${ }^{19}$ A maximum likelihood estimation algorithm was used to estimate the maximum likelihood of $W$. bancrofti infection at the $95 \%$ confidence level in mosquitoes, whereby total pools screened, the number of positive pools, and pool sizes was entered into Poolscreen 2 software to obtain infection rate. PoolScreen 2 software was obtained from the Depart- 
TABLE 1. Proportion of Mosquito Species Collected for the Detection of Wuchereria bancroffi in Selected Villages of Pangani District, Northeastern Tanzania

\begin{tabular}{lccc}
\hline Village & $\begin{array}{c}\text { Culex } \\
\text { quinquefasciatus } \\
\mathbf{n}\end{array}$ & $\begin{array}{c}\text { Anopheles } \\
\text { gambiae } \\
\text { sensu lato } \\
\mathbf{n}\end{array}$ & $\begin{array}{c}\text { Culex } \\
\text { cinereus } \\
\text { and Culex } \\
\text { pipiens } \\
\mathbf{n}\end{array}$ \\
\hline Bweni & 174 & 0 & 0 \\
Madanga & 300 & 0 & 1 \\
Meka & 180 & 0 & 0 \\
Msaraza & 137 & 0 & 0 \\
Pangani & 154 & 3 & 2 \\
West & $\mathbf{9 4 5}(\mathbf{9 9 . 3 6 \% )}$ & $\mathbf{3}$ (0.32\%) & $\mathbf{3}$ (0.32\%) \\
Total (\%) & & & \\
\hline
\end{tabular}

ment of Biostatistics and Division of Geographic Medicine, University of Alabama at Birmingham, USA. The programme relies on the fact that the PCR assay is sensitive enough to detect a single infected insect in a pool containing large numbers of uninfected insects.

\section{Ethical Considerations}

Ethical approval for this study was obtained from the Medical Research Coordination Committee (MRCC), based at the National Institute for Medical Research, Dar es Salaam, Tanzania (Ref: NIMR/HQ/R.8a/Vol. IX/1834). Permission to conduct study was also obtained from regional, district, and respective village authorities. Moreover, written informed consent was sought from the heads of the households where mosquito collection was carried out.

\section{RESULTS}

\section{Lymphatic Filariasis Vector Abundance}

A total of 951 female mosquitoes were collected: 174 from Bweni, 301 from Madanga, 180 from Meka, 137 from Msara$\mathrm{za}$, and 159 from Pangani West. Among the 951 collected mosquitoes, by far the majority $(99.36 \%)$ were Culex quinquefasciatus, followed by Anopheles gambiae (0.32\%), and Culex cinereus, and Culex pipiens (0.32\%) (Table 1).

\section{Presence of W. bancroffi in Mosquitoes}

All Cx. quinquefasciatus mosquitoes collected in Pangani District were screened for $W$. bancrofti infection. From 47 mos- quito pools screened for $W$. bancrofti, 24 (51\%) pools tested positive and $23(48 \%)$ tested negative. Positive pools produced a PCR product of approximately $188 \mathrm{bp}$, an expected size after Ssp I amplification using NV1 and NV2 primers. ${ }^{17}$ Figure 2 shows an example of the agarose gel after performing PCR for the detection of $W$. bancrofti in mosquito pools.

\section{Estimated Rate of Infection of W. bancrofti in Mosquito Vectors}

A total of 951 female mosquitoes were screened for infection with $W$. bancrofti using Poolscreen 2 software, which uses maximum likelihood at the $95 \%$ confidence level based on likelihood rates for determining the infection rates. ${ }^{19}$ Msaraza village had the highest estimated rate of infection, at 5.34\%, and Bweni village had the lowest estimated rate of infection, at $2.9 \%$ (Table 2 ).

\section{DISCUSSION}

Monitoring infection rates among humans and vectors is an essential component of any lymphatic filariasis control programme. Such monitoring informs decision making, for example, deciding when to stop MDA and to certify the elimination of the disease. Monitoring transmission or infection in vectors is ideal, as mosquitoes may offer a real-time estimate of transmission, ${ }^{20,21}$ even though the manifestation of microfilaria may be marginally quicker in humans. Low-level microfilaraemia may also not be easy to detect in human populations.

The results obtained from the present study indicate that $C x$. quinquefasciatus was the most abundant vector species caught during the study. These observations concur with a study carried out in Dar es Salaam, ${ }^{22}$ which reported that out of 12,096 vector mosquitoes caught using light traps, the great majority (99.0\%) were Cx. quinquefasciatus, followed by a few Anopheles gambiae (0.9\%) and Anopheles funestus (0.1\%).

The higher abundance of C. quinquefasciatus in the present study might be because mosquitoes were collected during the dry season, during which the overall mosquito population is normally relatively low. The observed mosquito abundance has important implications on the transmission of both malaria and lymphatic filariasis, but the low anopheline mosquito abundance observed in the present study has greater implications on malaria transmission.

Wuchereria bancrofti infection in mosquitoes was found in all 5 villages, with an overall infection rate of 3.3\%. Derua et al. ${ }^{12}$ reported that the overall rate of $W$. bancrofti infection among 3 sibling species - An. gambiae, Anopheles merus, and Anopheles arabiensis - in their study area in northern Tanzania, was $3.6 \%$, which is similar our calculated rate. It should be noted that these infection rates are based on all vector-borne stages of the parasite, since the PCR testing method used cannot distinguish between the different larval stages. There is a need to determine the presence of the infective stages of $W$. bancrofti to estimate the risk of lymphatic filariasis trans- 


\section{TABLE 2. Infection Rates of Mosquitoes with Wuchereria bancroffi, as Determined by Polymerase Chain Reaction Pool Screening}

\begin{tabular}{|c|c|c|c|c|}
\hline Village & $\begin{array}{c}\text { Mosquitoes } \\
\mathbf{n}\end{array}$ & $\begin{array}{c}\text { Screened Pools } \\
n\end{array}$ & $\begin{array}{c}\text { Positive Pools } \\
\text { n }\end{array}$ & $\begin{array}{c}\text { Estimated Rate of } \\
\text { Infection } \\
(95 \% \mathrm{Cl})\end{array}$ \\
\hline Bweni & 174 & 11 & 5 & $2.9(8.9-7.04)$ \\
\hline Madanga & 301 & 15 & 7 & $3.09(1.15-6.54)$ \\
\hline Meka & 180 & 7 & 4 & $4.15(1.04-1.08)$ \\
\hline Msaraza & 137 & 6 & 4 & $5.34(1.3-1.42)$ \\
\hline Pangani West & 159 & 8 & 4 & $3.4(8.6-8.79)$ \\
\hline Total & 951 & 47 & 24 & $\begin{array}{c}\text { Overall ERI } \\
3.3(2.13-5.37)\end{array}$ \\
\hline
\end{tabular}

Abbreviations: $\mathrm{Cl}$, confidence interval; ERI, estimated rate of infection

mission by these mosquitoes. ${ }^{23}$ The detection of infection in mosquito vectors is an indication that there may be infected humans in the area, and a high rate of $W$. bancrofti in the vectors might reflect a high prevalence of microfilaraemia in the human population. A previous study reported the overall prevalence of $24.5 \%$ for $W$. bancrofti microfilaria among people over the age of 1 year..$^{24}$ In a similar study, the prevalence of $W$. bancrofti-specific circulating antigen was $53.3 \%{ }^{24}$

While annual MDA remains the standard intervention for interrupting the transmission of lymphatic filariasis, vector control to reduce the number of potential mosquito vectors is increasingly recognised as a complementary strategy in some contexts..$^{25} \mathrm{~A}$ combination of more than 1 vector control method would probably enhance the impact on vector populations and lymphatic filariasis transmission reduction, particularly if the methods address different stages of the mosquito lifecycle or if they have different modes of action. To further explore the findings and implications of this study, we recommend that further research - with much larger sample sizes and encompassing parasites from different geo-climatic regions - be conducted to enhance our understanding of $W$. bancrofti vector infection status. Additionally, further research comparing the prevalence of $W$. bancrofti in the human population with that among mosquito vectors in the study area and other endemic areas is of paramount importance, to draw clear conclusions regarding $W$. bancrofti infection prevalence in Tanzania.

\section{CONCLUSION}

A high $W$. bancrofti vector infection rate of 3.3\% was found in the present study, indicating a high likelihood of human infection in the area. Most mosquitoes collected were $C x$. quinquefasciatus, which calls for integrated mosquito control interventions to lower the risk of $W$. bancrofti transmission from mosquitoes to humans. Additional research is needed to gain an in-depth understanding of the $W$. bancrofti larval stages in mosquitoes, their drug sensitivity and susceptibility profiles, and fecundity. Such information would inform treatment strategies and decision making relaed to, for example, how long to run MDA programmes and the optimal size of the human population treatment unit.

Acknowledgements: I am grateful to Dr Yusuph Makange, the District Neglected Tropical Diseases Coordinator of Pangani. My gratitude also goes to Miss Mariam Makange for providing the invaluable skilled laboratory assistance, as well as Mr Bernad Batenga and Demitrius Max for assisting with mosquito collection and identification.

The study received financial support from the Tanzania Commission of Science and Technology (COSTECH).

\section{REFERENCES}

1. Manguin S, Bangs MJ, Pothikasikorn J and Chareonviriyaphap T. Review on global co-transmission of human Plasmodium species and Wuchereria bancrofti by Anopheles mosquitoes. Infect Genet Evol. 2010;10(2):159-177. CrossRef. Medline

2. Pfarr KM, Debrah AY, Specht S and Hoerauf A. Filariasis and lymphoedema. Parasite Immunol. 2009;31 (11):664-672. CrossRef. Medline

3. Bockarie MJ, Taylor MJ, Gyapong JO. Current practices in the management of lymphatic filariasis. Expert Rev Anti Infect Ther. 2009;7(5):595-605. CrossRef. Medline

4. Simonsen PE. Filariases. In: Cook GC, Zumla Al, eds. Manson's Tropical Diseas es. 22nd ed. London: Saunders Elsevier Limited; 2009. p. 1477-1513.

5. Bartholomay LC, Christensen BM. Vector-Parasite Interactions in Mosquito-Borne Filariasis. In: Klei TR, Rajan TV, eds. World Class Parasites: Volume 5 - The Filaria. Boston: Kluwer Academic Publishers; 2002. p. 9-19.

6. VanHoegaerden $M$, Ivanoff B. A rapid, simple method for isolation of viable microfilaria. Am J Trop Med Hyg. 1986;35(1):148-151. CrossRef. Medline

7. Zhong M, McCarthy J, Bierwert L, et al. A polymerase chain reaction assay for the detection of the parasite Wuchereria bancrofti in human blood samples. Am J Trop Med Hyg. 1996;54(4):357-363. CrossRef. Medline 
8. Amaral F, Dreyer G, Figueredo-Silva J, et al. Live adult worms detected by ultrasonography in human Bancroftian filariasis. Am J Trop Med Hyg. 1994;50(6):753-757. CrossRef. Medline

9. Simonsen PE, Malecela MN, Michael E, Mackenzie CD, eds. Lymphatic Filariasis Research and Control in East and Southern Africa. Copenhagen, Denmark: DBL - Centre for health Research and Development; 2008. https://ivh.ku.dk/ english/research/about_parasitology_and_aquatic_diseases/docs/283794_ lymphatic_filariasis.pdf. Accessed 21 March 2019.

10. Malecela MN, Kilima P, Mackenzie CD. Implementation and management of lymphatic filariasis control and elimination programmes: the Tanzanian experience. In: Simonsen PE, Malecela MN, Michael E, Mackenzie CD, eds. Lymphatic Filariasis Research and Control in East and Southern Africa. Copenhagen, Denmark: DBL - Centre for health Research and Development; 2008. p. 112-123. https://ivh.ku.dk/english/research/about_parasitology_and_aquatic_diseases/docs/283794_lymphatic_filariasis.pdf. Accessed 21 March 2019.

11. Simonsen PE, Magesa SM, Dunyo SK, Malecela-Lazaro MN, Michael E. The effect of single dose ivermectin alone or in combination with albendazole on Wuchereria bancroffi infection in primary school children in Tanzania. Trans $R$ Soc Trop Med Hyg. 2004;98(8):462-472. CrossRef. Medline

12. Derua YA, Alifrangis $M$, Hosea $K M$, et al. Change in composition of the Anopheles gambiae complex and its possible implications for the transmission of malaria and lymphatic filariasis in north-eastern Tanzania. Malaria J. 2012;11:188. CrossRef. Medline

13. Simonsen PE, Derua YA, Magesa SM, et al. Lymphatic filariasis control in Tanga Region, Tanzania: status after eight rounds of mass drug administration. Parasit Vectors. 2014;7:507. CrossRef. Medline

14. Mboera LI, Kihonda J, Braks MA, Knols BG. Short report: Influence of centers for disease control light trap position, relative to a human-baited bed net, on catches of Anopheles gambiae and Culex quinquefasciatus in Tanzania. Am J Trop Med Hyg. 1998;59(4):595-596. Medline

15. Edwards FW. Mosquitoes of the Ethiopian Region. III. Culicine Adults and Pupae. London: British Museum; 1941. http://mosquito-taxonomic-inventory.info/ sites/mosquito-taxonomic-inventory.info/files/Edwards\%201941. pdf Accessed 21 March 2019

16. Gillies MT and Coetzee M. A supplement to the anophelinae of Africa south of the Sahara (Afrotropical Region). Publ S Afr Inst Med Res. 1987;55:1-43.

17. Chanteau $S$, Luquiaud $P$, Failloux $A B$, Williams SA.Detection of Wuchereria bancroffi larvae in pools of mosquitoes by the polymerase chain reaction. Trans R Soc Trop Med Hyg. 1994;88(6):665-666. Medline
18. World Health Organization (WHO). Lymphatic Filariasis: A Handbook of Practical Entomology for National Lymphatic Filariasis Elimination Programmes. Geneva: WHO; 2013; https://www.who.int/lymphatic_filariasis/resources/9789241505642/en/. Accessed 21 March 2019.

19. Katholi CR, Toé L, Merriweather A, Unnasch TR. Determining the prevalence of Onchocerca volvulus infection in vector populations by polymerase chain reaction screening of pools of black flies. J Infect Dis. 1995;172(5):1414-1417. Medline

20. Plichart C, Sechan Y, Davies N, Legrand AM. PCR and dissection as tools to monitor filarial infection of Aedes polynesiensis mosquitoes in French Polynesia. Filaria J. 2006;5:2. CrossRef. Medline

21. Goodman DS, Orelus JN, Roberts JM, Lammie PJ, Streit TG. PCR and Mosquito dissection as tools to monitor filarial infection levels following mass treatment. Filaria J. 2003;2(1):11. CrossRef. Medline

22. Mwakitalu ME, Malecela MN, Pedersen EM, Mosha FW, Simonsen PE. Urban lymphatic filariasis in the metropolis of Dar es Salaam, Tanzania. Parasit Vectors. 2013;6:286. CrossRef. Medline

23. Laney SJ, Ramzy RM, Helmy HH, et al. Detection of Wuchereria bancrofti L3 larvae in mosquitoes: a reverse transcriptase PCR assay evaluating infection and infectivity. PLoS Negl Trop Dis. 2010;4(2):e602. CrossRef. Medline

24. Simonsen PE, Pedersen EM, Rwegoshora RT, Malecela MN, Derua YA, Magesa SM. Lymphatic filariasis control in Tanzania: effect of repeated mass drug administration with ivermectin and albendazole on infection and transmission. PLoS Negl Trop Dis. 2010;4(6):e696. CrossRef. Medline

25. van den Berg H, Kelly-Hope LA, Lindsay SW. Malaria and lymphatic filariasis: the case for integrated vector management. Lancet Infect Dis. 2013;13(1):8994. CrossRef. Medline

\section{Peer Reviewed}

Competing Interests: None decleared.

Received: 29 Aug 2018; Accepted: 17 Mar 2019

Cite this article as: Materu GS. Prevalence of Wuchereria bancrofti Infection in Mosquitoes from Pangani District, Northeastern Tanzania. E Afr Sci. 2019;1 (1):3034. http://doi.org/10.24248/EASci-D-18-00003.

(C) Materu. This is an open-access article distributed under the terms of the Creative Commons Attribution License, which permits unrestricted use, distribution, and reproduction in any medium, provided the original author and source are properly cited. To view a copy of the license, visit http://creativecommons.org/licenses/by/4.0/. When linking to this article, please use the following permanent link: http://doi. org/10.24248/EASci-D-18-00003. 